\title{
THE SOCIOECONOMIC BURDEN OF BURULI ULCER DISEASE IN THE GA WEST DISTRICT OF GHANA 1
}

\author{
Adobea Yaa Owusu \\ Institute of Statistical, Social and Economic Research \\ University of Ghana, Legon, Ghana \\ Email: gaowusu@ug.edu.gh; yaa_owusu@hotmail.com \\ and \\ Clement Adamba \\ Institute of Statistical, Social and Economic Research \\ University of Ghana, Legon, Ghana \\ Email: clementadamba@yahoo.com \\ Doi:10.4314/gdjs.v9.i1.1
}

\begin{abstract}
Buruli ulcer (BU) is the third most common mycobacterial infection in humans after tuberculosis and leprosy. We highlight the social and economic burden of $86 \mathrm{BU}$ patients studied in a Ghanaian district in 2008 which has the fifth highest BU prevalence rate in the country and is the most endemic in the Greater Accra Region. We traced patients who had received treatment for $B U$ within the year preceding the study and interviewed them or the primary caretakers of minors mostly using a semi-structured interview guide. We found that against a background of living in abject poverty, the affected households spent on average over 80 per cent of their annual incomes on seeking health care for the disease despite the policy of free treatment for BU in government health care institutions. Beyond the direct financial costs, households incurred huge social and psychological burdens such as social stigma, isolation, and even divorce. Labor time lost due to care-seeking came close to one year for some affected patients. The extent of the burden from the disease had a relationship with care seeking patterns for the disease. We recommend that $B U$ affected households be enrolled in the social protection programs of Ghana.
\end{abstract}

KEY WORDS: Buruli ulcer, socioeconomic burden, stigma, poverty, Ghana

\section{INTRODUCTION}

Buruli Ulcer (BU) has been around since at least the 1800s. Yet, very little is known about its mode of transmission. It was only in 2006 that the WHO identified a mycobacterial ulceran as the causative organism of the disease. Thus, the disease is shrouded mostly in uncertainties. Furthermore, BU has been identified as the third most common mycobacterial infection in humans after tuberculosis and leprosy (WHO, 2006). BU is more prevalent in the tropics and the

\footnotetext{
${ }^{1}$ a) The authors are grateful to Dr. I. Osei-Akoto of the Institute of Statistical, Social and Economic Research (ISSER), University of Ghana, Legon, for reviewing an original draft of this article.

b) This paper benefited from grants from the International Development Research Center (IDRC), Canada under the Think Tank Initiative. The views expressed herein do not necessarily represent those of the IDRC or its Board of Governors.
} 
subtropics. In Africa, it is more endemic in the West and particularly more prevalent in Benin, Cote d'Ivoire, Ghana, Guinea, Liberia, Nigeria, Sierra Leone and Togo (WHO, 2006). According to WHO's statistics, Ivory Coast has recorded 24,000 cases with Ghana recording 11,000 cases while Benin has recorded 7,000 confirmed cases (WHO, 2006).

If the disease is identified early, treatment is relatively easy. The use of rifampicin and streptomycin is noted to have a positive impact on treatment outcomes (Amofah, Asamoah \& Afram-Gyening, 1998; WHO, 2004; Etuaful, Carbonnelle, Grosset, Lucas, Horsfield, Phillips, Evans, Ofori-Adjei, Klutse, Owusu-Boateng, Amedofu, Awuah, Ampadu, Amofah, Asiedu \& Wansbrough-Jones, 2005;). It has the potential of curing small lesions and limiting surgical acts for large lesions. Until this discovery, treatment largely required surgery which often involves extensive excision, sometimes with skin transplantations. But if the disease is reported late and there is an extensive necrosis of the skin or an attack on the bone the only option is extensive surgical treatment with skin grafting, which may involve amputation of affected limbs and protracted physiotherapy.

In Ghana, health care officials have diagnosed the disease since 1969 (Montoro, Capo, Rodriguez, Ruiz \& Llop, 1997). As at 2002, the national prevalence rate of BU was 20.7 per 100,000 . The disease is found in all the ten regions of Ghana, and in 90 of the 110 districts in the country. The prevalence rate of BU in Ghana is about twice that of leprosy ( 9 per 100,000 ). The most endemic districts have a prevalence rate of as high as 150.8 per 100,000 . BU is, however, more prevalent in the southern belt, that is, Ashanti, Central, Western and Eastern regions, than the north (Amofah, Bonsu, Tetteh, Okrah, Asamoah, Asiedu \& Addy, 2002).

While the free treatment policy undoubtedly provides a buffer to BU patients and would potentially encourage them to report early and possibly avoid huge financial burdens related to direct and indirect costs such as the cost of transportation, the associated long period of stay in the hospital coupled with the loss of earnings and work opportunities for patients (and possibly caretakers), and the stigma associated with the perceived cause of the disease, serve as barriers to benefitting from the national free treatment policy. In fact, solutions to these indirect costs are difficult to come by.

Conceptualizing with a focus on the socioeconomic burden is important in helping us appreciate in a more holistic manner how BU affects people, impoverishes households and perpetuates poverty. While there is an appreciable amount of information on the economic burden of the disease in Ghana (Asiedu \& Etuaful, 1998), there is very little on the social burden, including the burden of stigma that households have to face. The social burden of any disease is intricately linked to the economic burden, and further compounds how households mobilise resources to cope with the burden of the disease. The socioeconomic outcome of an ill-health condition in a household, depending on the effectiveness of the coping strategies adopted, could either be impoverishment (sometimes a breakdown of the household as a socioeconomic unit) or stable wellbeing. The costs that accompany BU treatment, its disabling outcomes, coupled with its associated stigma can cause a process of household impoverishment. BU disables, leading to loss of income and productive person-hours. This means that being afflicted with BU is likely to force household members to cut the consumption of their basic needs, trigger productive asset sales or high levels of debt in order to cope. A household's capacity to cope with BU can further be undermined because its associated stigma generates social exclusion, weakens support networks, and use of community resources.

In this paper, we focus on the socioeconomic burden of BU on affected households, including direct and indirect costs, the burden of stigma associated with the disease, as well as the implications for poverty. In so doing, we expand our knowledge on the burden of BU that includes stigma and contribute to major discussions on how households cope with illness in developing countries. Among others, an insight to the socioeconomic burden of BU could help 
community members and health care workers empathize with BU victims, offering them the needed respite. Discussing the socioeconomic burden would also generate further policy debates on care for BU in Ghana and West Africa where the disease is largely endemic. The remaining sections are on the relationship between BU and poverty, the methodology, including the study area, findings, and discussion, including the implications of our findings for poverty reduction.

\section{OVERVIEW OF LITERATURE}

\section{Relationship between BU and Poverty}

Illness is one of the most important factors associated with poverty, particularly in developing countries. Illness diminishes health status, drains incomes and impoverishes households. It is widely recognized that serious illness imposes significant adverse effects on household labour supply and income generation. It has been found that illness affects largely household income generation, food production, labour-time allocation and access to productive assets as well as children's education (Ding, Chen, Feng \& Li, 2008).

The burden of an illness can be categorized into two components: economic and social (Adamba \& Owusu, 2011). Economic burden consists of the direct cost of illness which is always seen in terms of the medical cost of treating a particular illness (cost of drugs, hospitalization, laboratory test, surgery, and so forth), and the indirect cost which includes the opportunity cost of time lost to the patient seeking health care, the accompanying caretaker if there is any, and any cost of change in accommodation or feeding pattern due to the illness. Serious illness that involves long periods of hospitalization and requires an accompanying caretaker such as BU engenders huge direct and indirect costs as these persons are often unavailable to contribute to the productivity of their households.

A number of studies on Ghana and elsewhere have noted BU's very high tendency to drift households into poverty, directly and indirectly. Studying treatment costs for 26 confirmed BU patients in Victoria, Australia, in 1997 and 1998, Drummond and Butler (2004), observed that the cost of treatment was extremely expensive, directly and indirectly. They found that the direct costs of treatment per patient was $\$ 6,800$ for mild cases, and $\$ 27,681$ for severe cases, and also recorded that $61 \%-90 \%$ of the costs their patients incurred was in relation to hospitalization. Specific to Ghana, Mumma, Whitney, Dadzie, Etuaful and Ampadu (2003) documented in their study of BU patients, that the disease caused even the affected households that were not poor before the infection, to drift into poverty. Again, studying the socioeconomic cost of treating BU infection on households in Ghana over three years, Asiedu and Etuaful (1998) specified that the direct cost of treating the disease per patient per year was up to an average of \$967. Kofie, Attua and Nabila (2008) acknowledge that the disease makes the patients they studied in the Ga West District poor, while Adamba and Owusu (2011) found in the same Ga West District that the BU households they studied got poorer due to the disease and coped by selling tangible family assets and reduced their farm sizes, among other strategies, all of which plunged the study households into further poverty.

Further to this, some studies in Ghana and other countries have found the indirect cost of BU to be high; sometimes, even more than half of its total cost (Asiedu \& Etuaful, 1998; Stienstra, van der Graaf, Asamoah \& van der Werf, 2002; Drummond, Butler \& James, 2004; Kofie, Attua and Nabila, 2008). Asiedu and Etuaful (1998) specified with reference to BU in Ghana, that the indirect cost of the disease was up to $79 \%$ of the total cost of the disease per patient per year. This included average hospitalization of up to 186 days per patient in one year. Drummond and Butler's study in Australia found a separate indirect cost of BU of up to $24 \%$ (which was included in the total cost of hospitalization of up to $90 \%$ which they had accounted for under indirect costs) for the patients they studied. Amputations, permanent physical deformities and 
related complications, including blindness in some patients, and even death, were some indirect costs suffered by some of the BU patients that Asiedu and Etuaful (1998) studied in Ghana.

The social burden of BU has also been found to produce other indirect costs, including a reduction in the labor force which causes an increase in the dependency ratio of households and the society at large (Adamba \& Owusu, 2011), over reliance on social networks and stigmatization, in some cases (Stienstra et al., 2002). In an earlier study in Ghana, Stienstra and associates (2002) documented that BU was among the diseases sometimes attributed to witchcraft and curses for aberrant social behaviour either by oneself or the family. Due to these superstitious perceptions, BU afflicted persons are often stigmatised in society and largely avoided or neglected. Stienstra and associates (2002) found that the BU patients they studied tended to display shame, embarrassment and low self-esteem due to their infection. Among others, these indirect costs tended to also impoverish the BU victims studied by causing them to lose their jobs and/or to give up their jobs voluntarily, given the social stigma the affected household members experienced. Based on the foregoing, BU has been found to lead to poverty both directly and indirectly, including related opportunity costs to BU infected persons, their households, and society at large.

\section{Coping Strategies}

Strategies often adopted to cope with the direct cost of illness include borrowing, selling assets, and use of available savings. Coping with indirect cost also involves intra-household labor rearrangements, and the reduction in farm sizes, among others. Stigmatised people and their households also adopt several mechanisms to cope with the source of stigma. Miller and Kaiser (2001) noted that stigmatised people have a vast array of responses to stressors resulting from their diminished social status, including emotional, cognitive, biological, and behavioural responses. Some of these could either be problem-solving (active coping styles) or emotionfocused (passive coping styles such as avoidance) (Miller \& Kaiser, 2001; Coetzee \& Spangenberg, 2003; Makoae, Greef, Phetlhu, Uys, Naidoo, Kohi, Dlamini, Chirwa \& Holzemer, 2008). Makoae and others (2008) for instance found that $55.1 \%$ of the coping strategies of HIV/AIDS infected people they studied adopted were problem-solving and $44.9 \%$ were emotion-focused. Some of the emotion-focused strategies they noted included rationalization (e.g. seeing the illness as any other illness, saying that after all everybody will die one day, etc.), turning to God (e.g. relying on prayers), and hoping (e.g. living with hope). Problem-solving strategies included changing lifestyles, joining groups, and going for counseling.

Some of the coping strategies discussed earlier on have been noted to be potentially 'risky' for the future welfare of households (Russell, 1996; Wilkes, Hao, Bloom \& Xingyuan, 1997). Coping strategies such as sale of assets can lead to asset depletion and asset poverty, while repayment of loans with high interest rates can lead to inescapable debt burden on the household. Prejudice can also increase peoples' anxiety and affect the quantity and quality of health care they receive (Allison, 1998; Clark, Anderson, Clark \& Williams, 1999). Disease stigmatisation has an intricate link with health-seeking behaviour, and impacts heavily on costs and treatment outcomes (Brown, Trujillo \& Macintyre, 2001). Due to the social interpretation given to a disease such as HIV/AIDS for example, persons infected tend to avoid people, while their initial treatment strategies involve the use of herbs, self-medication, and purchase of drugs over the counter (Awusabo-Asare \& Anarfi, 1997). This leads to delays in reporting the infection for early attention thus enlarging the enormity of coping that is required. Hoffman (1996) noted that, the relationships between health status, stigma, and ways of coping with HIV infection was inherently stressful and had a major influence on the quality of life. 


\section{METHODS}

\section{Study Area and Source of Data}

The Ga West District is located in the Greater Accra Region of Ghana. About 70 per cent of the population in the District is engaged in agricultural activities, making farming its major economic activity. The District has the highest number of reported cases of BU in the Greater Accra Region, and the fifth most BU endemic district in the country. Amofah and associates (2002) documented a BU prevalence rate of 87.7 per 100,000 persons in 1999 . BU treatment is free of medical charges in Ghana and the District Health Centre at Amasaman has a special unit that provides curative services for BU cases. However, the majority of the endemic communities in the District lack access to quality health care. The poor distribution of health facilities relative to the area's endemicity for the BU disease is particularly noteworthy, and has implications for health seeking behaviour, cost of health care and coping strategies. There are eight health facilities in the District, with health care mainly provided by the state through the Ministry of Health and Ghana Health Service, although there are a number of private clinics and family planning and maternity homes. Health care to rural communities is augmented by outreach services provided on monthly basis by the Ghana Health Service.

The data for this study were collected from $86 \mathrm{BU}$ patients and primary caretakers/head of households if minors ( 15 years and below) were involved, using purposive sampling. We traced the affected communities and households using records from the district government hospital to reach interviewees. We mostly administered a semi-structured questionnaire which made room for qualitative answers as well. In addition, we conducted an in-depth interview with the Ga West Area Development Program Officer for World Vision International (WVI) in-charge of health programmes. WVI is an international non-governmental organization with an office in the District. The interview with the latter covered a wide range of issues including various interventions of WVI with respect to identification and treatment of BU in the District.

\section{FINDINGS}

\section{Characteristics of the Study Population}

The household respondents were predominantly poor, and typically lived in the rural parts of the District (94.2\%). The mean annual income of a typical household in the District was GH $\$ 40.70$ with an annual per capita income of GH\$98, which is below the poverty line². Furthermore, about 22.1 per cent of the BU affected persons were farmers, while more than 60 per cent $(61.6 \%)$ of them came from agriculture-dependent households. About 57 per cent of affected persons were pupils or students and 7 per cent were unemployed.

Most (63.9\%) of the BU affected persons were largely less educated with just 2.3 per cent completing tertiary education (Table 1 ). About 34 per cent $(33.7 \%)$ of the BU patients had received or were receiving primary education. A similar proportion $(31.4 \%)$ of patients who were old enough ( 6 years or more) to attend school or to have completed at least a terminal level of education were found to have no formal school education. The rest (2) were children below school going age (i.e., below 6 years).

There was no variation in the sex distribution of the infected patients. More males (51\%) were infected compared to females (49\%). While about 49 per cent (48.8\%) of those infected were below 15 years old, approximately 51 per cent of the rest were above 15 years. About 30.2 per cent were children in the age range of one to 10 years and 18.6 per cent were between the ages of 11 and 15 years. Most (92.7\%; 38 out of 41) of the infected children were within the school-

\footnotetext{
${ }^{2}$ During the time of data collection, the Ghana cedi had about the same value as the United States dollar.
} 
going age (six to 17 years old) and to be infected with BU means being absent from school for a considerable period of time and consequently dropping out of formal schooling if medical care was not sought early. The implications of this for future development can be far reaching for the children and their households.

Table 1: Socio-Demographic characteristics of BU patients interviewed

\begin{tabular}{|l|l|l|}
\hline Variable & Attribute & Percentage \\
\hline Sex & Male & 51.2 \\
& Female & 48.8 \\
& $1-10$ & 30.2 \\
& $11-15$ & 18.6 \\
Educational level attained* & $16-35$ & 31.4 \\
& $36-65$ & 19.8 \\
& & \\
& None & 31.4 \\
& Primary & 33.7 \\
& JSS/MLSC** & 18.6 \\
& Sec/tech & 11.6 \\
& Tertiary & 2.3 \\
& & \\
& Farmer & 22.1 \\
& Trader & 5.9 \\
& Gov. employee & 2.3 \\
& Driver & 3.5 \\
& Carpenter/Mason & 2.3 \\
& Pupil/student & 57.0 \\
& Unemployed & 7.0 \\
& Urban & 5.8 \\
& Rural & 94.2 \\
\hline
\end{tabular}


Source: Authors' survey, 2008

*Two of the BU patients (2.4\%) were children below school going age and thus excluded from the analysis on education.

**JSS/MSLC means Junior Secondary School/Middle School Leaving Certificate

\section{Socio-economic Burden of BU}

Compared to malaria for instance, the prevalence of BU in a community would be rather low, but its consequences, both economic and social, are enormous and crippling. The disease causes physical and financial disabilities in households. The treatment of the disease is very expensive in terms of time loss and financial implications to households and the government.

\section{Economic Burden}

The cost in time and loss of labour is economically disabling of the household. Patients who reported directly to the District Health Centre (DHC) and/or the WVI's health facility in the District for care paid no money for medical care, but bore the cost of transportation and also incurred a huge number of working days/hours loss due to hospitalization. Persons who tried other means of treatment elsewhere (self-medication, bought over-the-counter drugs, visited herbalists, etc.) (Figure 1), however, incurred both financial and non-financial costs.

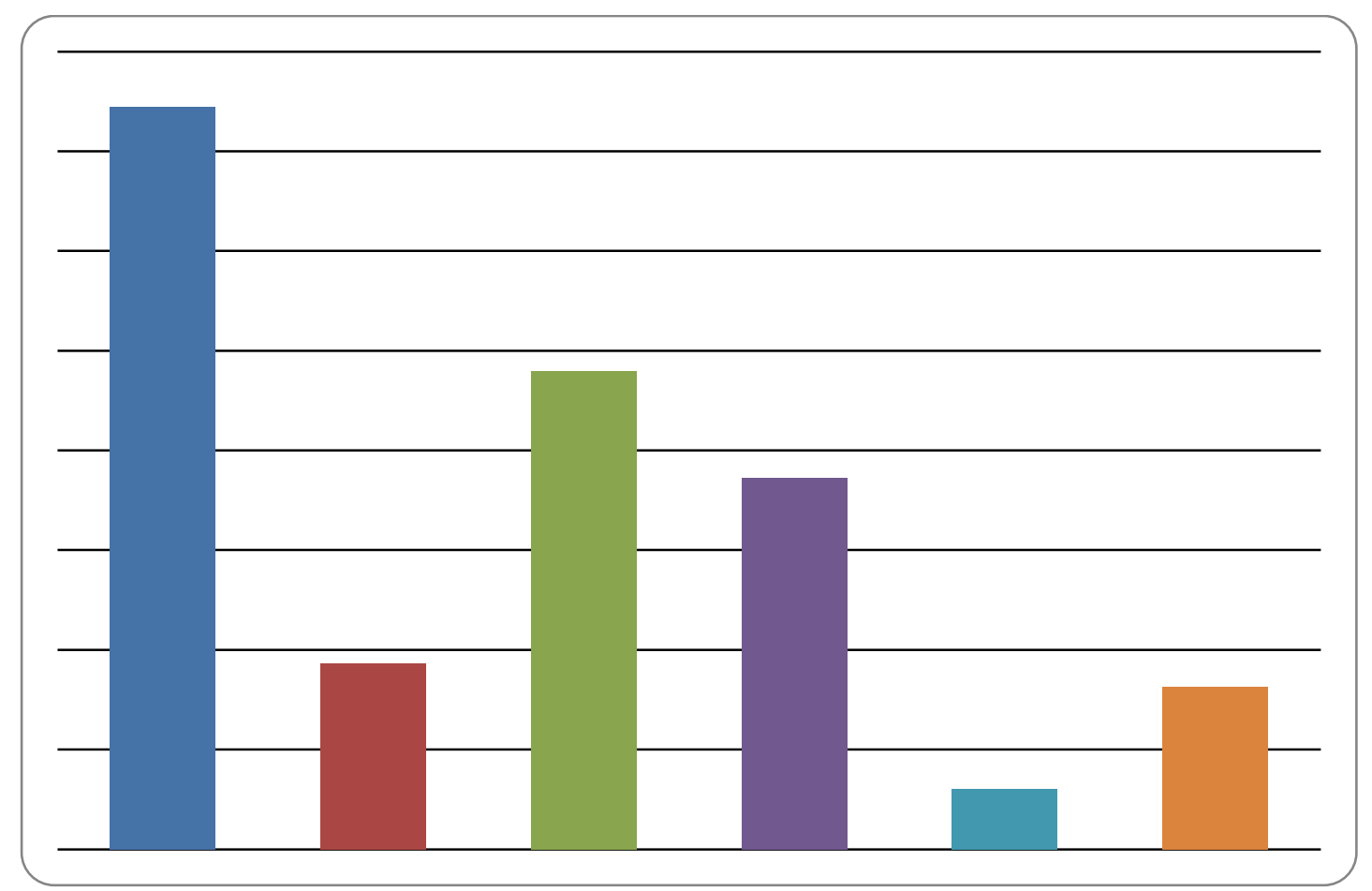

Figure 1: First Response to Change in Body Structure/Colour

Source: Authors' survey, 2008

We found that a total of $67(79 \%)$ of the BU infected persons sought treatment elsewhere before reporting at the DHC (Figure 1). Of this number, 54 per cent visited a traditional healer. Close to 39 per cent resorted to self-medication while others (2\%) sought prayers from pastors for deliverance from the purported spiritual cause of BU.

For those who sought treatment elsewhere before reporting at the DHC, the average total cost of treatment from other places was GH\$94 per household. Direct cost constituted about 62 per cent while indirect cost formed the remaining 38 per cent. Direct cost was incurred due to direct 
herbal treatment, drugs bought (self-medication), and care from a private clinic. It cost a household about $\mathrm{GH} \$ 36$ to receive treatment from herbalists and $\mathrm{GH} \$ 385$ from a private clinic.

For treatment at the DHC, the patients' cost of transportation was mostly borne by the WVI by sometimes reimbursing the fares of patients who went to the hospital for sore dressing and, providing accommodation and food (one meal for patients). The cost of transportation was sometimes a huge challenge for some households and mostly explained the patients' inability to take advantage of the free medical care. This difficulty with bearing the cost of transportation sometimes prevented some of them from going to dress their sores. On the average, a household spent a total of GH\$100 on transportation to the DHC for sore dressing alone during the entire period of seeking treatment for BU.

Additionally, the background of the victims had an intricate relationship with the economic burden of the disease. At least 95.3 per cent of the adult victims were self-employed. Given this, the loss of economic time meant loss of income, resulting in opportunity costs to patients and their households. Again more than 50 per cent of heads of households themselves were afflicted with the disease. This means a great deal of loss to the entire household.

\section{Labour Lost/Time Spent Treating the Disease}

A related dimension of the economic burden of the disease is the loss of labor to the household due to temporary unavailability of infected persons as a result of hospitalization and loss of other household members due to their role as caretakers of patients. Treatment of the disease at the DHC involves about eight weeks of mandatory hospitalization (under the directly observable treatment method recommended by the WHO). After eight weeks, patients whose conditions are severe (plague oedema and ulcers) and need surgery are further hospitalized and prepared for the necessary treatment processes. We found that in all, 17,661 days was spent by households seeking treatment for all the $86 \mathrm{BU}$ cases studied. On the average, households spent 205 days seeking treatment. This includes treatment sought elsewhere before coming to the hospital, hospitalization at the DHC and coming for wound dressing after discharge. The mean days spent by a patient who was hospitalized for treatment at the DHC was 167 days. In addition, a patient who had to report for review and sore dressing spent approximately 33 days ${ }^{3}$. Patients with severe cases of the disease lost approximately 180 days in all receiving treatment ${ }^{4}$.

The number of days spent receiving treatment varies according to the stage of the sickness presented at the health facility (Figure 2). A patient with a nodule spent approximately 74 (73.67) days receiving treatment (treatment period). Such a patient was likely to be hospitalized for 67 (66.67) days, and would spend only a minimum of 6 days reporting for sore dressing. People who come with nodules were likely to lose 78 (77.89) days of productive working time if employed. This differs quite markedly from that of an episode presented in an ulcerating stage. An ulcer case spent a total of 301 days receiving treatment at the health facility; hospitalized for nearly 251 days, and came in 44 days to receive wound dressing. Patients with ulcers lost approximately 265 (264.5) days of productive time.

\footnotetext{
${ }^{3}$ The number of days stayed in hospital and the number of days of sore dressing will not add up to total number of days spent seeking treatment because total days refers to total number of days victim started treatment of the disease up to the day of complete discharge

${ }^{4}$ Lost days refers to only days that victim was unable to engage in any economic activity at all.
} 


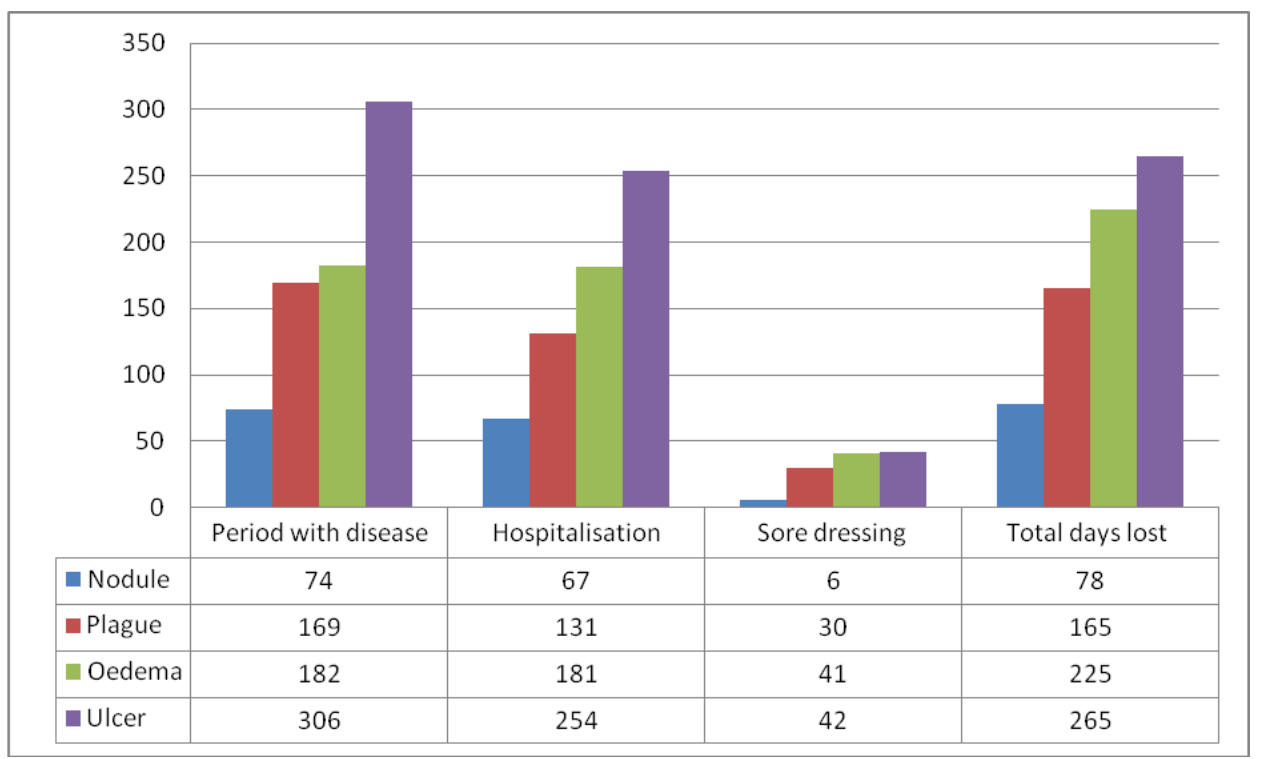

Figure 2: Days Spent Receiving treatment and days lost

Source: Authors' survey, 2008

An individual who reported with a plague spent approximately 169 days receiving treatment. She or he was likely to be hospitalized for 130 days, visit the health facility 30 times for sore dressing and was most likely to lose 165 days of productive working days. Someone who reported when the disease was in the oedematous stage spent a total of 229 days for the treatment, and was likely to have been hospitalized for 182 days. This individual would have also spent 41 days for sore dressing and was likely to lose 225 working days whilst receiving treatment.

\section{Psychosocial burden}

A third dimension of the socioeconomic burden is intangible and less emphasized, but is critically associated with poverty. BU engenders a lot of psychological, emotional, cognitive and behavioural troubles for both the individual and the household. We found a great deal of stigma associated with the disease among our respondents (Figure 3). As documented by Stienstra and others (2002), many of our respondents suggested that any person infected with the disease must have either been bewitched or was suffering the repercussions of a curse from God or the gods of the land. As a result of this many people, including whole families, felt stigmatized.

Many of them felt they were being avoided or rejected and treated with disdain by other people. Respondents were asked whether they have suffered or they perceive any change in attitude or behaviour of people towards them or their households since their illness became known publicly. Out of the 86 respondents (victims and parents/caretakers), 61 per cent answered in the affirmative suggesting that they had suffered or were suffering a real or perceived negative change in attitude towards them. Five BU patients got separated from their spouses or got divorced due to the difficulties associated with the disease. 


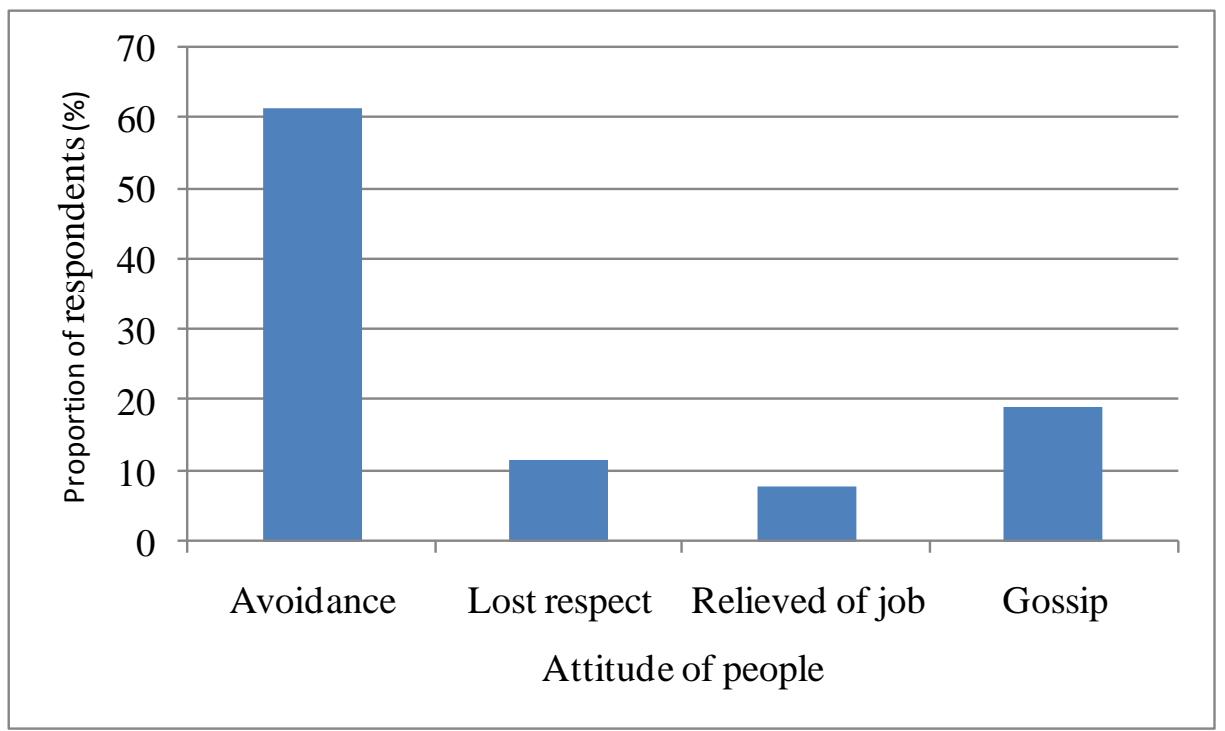

Figure 3: Perceived change in attitude towards BU victims or family (\%)

Source: Authors' survey, 2008. $\mathrm{N}=53$

Over 60 per cent of those who suggested that they had noticed a change in behavior of people towards them said people avoid their presence. Nearly 20 per cent noted that people gossiped about them and more than 10 per cent indicated that they had lost respect in the eyes of people because of the disease. About eight per cent of those who were not self-employed thought they were relieved of their jobs because of the disease. Those who complained of being avoided indicated that they were no longer welcomed to sit or chat with their friends. One patient commented thus:

For the period of my sickness and even now, I have no friends. Even my own colleague drivers are not happy when I am around them. Immediately I come around the lorry station, especially under the tree, then one by one they will get up and walk away pretending to be doing one thing or the other (BU victim who was a driver).

Another patient indicated that:

Nobody buys from me these days because of this disease that I suffered. Now the sore is healed yet I am unable to get my customers back. I am considering leaving this place to Accra central where they people will not know me or may be go back to my home town in the Volta Region (a female victim, who sells food stuffs).

Parents whose wards had the disease also said they were avoided and that people gossiped about them. Although respondents were not able to tell what the gossip was about, they still suspected quite strongly that people talk about them based on the way they observe their demeanour when approaching them.

When people are saying negative things about you, it is easy to detect from their demeanour when you come closer to them. Sometimes the way they laugh in chorus or greet you, can tell you that these people are gossiping about you. Besides, you know us women and our gossiping. We like to say little little things that do not concern us about people. Because of all these things I don't feel comfortable fetching water at the public bore-hole during the day or when people are there. I only fetch water when it is a little bit dark (a female parent of BU patient). 
Thus, the BU patients and their households in general felt that the disease has interrupted their social lives nearly permanently, and were either seeking ways to redress such social stigma, or in some cases, had adjusted to such stigma by withdrawing from some of their previous social groups and also from some routine activities.

\section{The Gender Dimension of the Burden of BU:}

Generally, men felt more stigmatised than women. More than 50 per cent of those who reported having suffered one form of stigma or the other were men. But in terms of those who felt that people gossiped about them, 80 per cent were women. All the persons who suffered marital separation or divorce were also women. One woman said she was driven away by her husband with the support of his extended family members. She explained:

My husband came back one evening and told me that the healer said the curse on me was very powerful and that he (herbalist) was not going to be able to heal me. The herbalist added that nobody else would be able to help me. So he (my husband) suggested that I go to my home town in the Volta Region to seek cure. A week later his sister came to the house and asked me whether I was not advised to go and seek treatment from my home town. In fact, the pressure was too much that I had to leave and stay with some distant family members in Accra until I was brought to the Amasaman DHC.

This highlights the level of insecurity and vulnerability that women particularly are susceptible to in many spheres of life (social, economic and health). But in the specific case of the disease, women suffer this fate because of the perception that the disease is associated with witchcraft and curses. As noted by Stienstra and others (2002) there is a strong perception that the disease is caused by witches or an individual is cursed with the disease. Owing to this perception, persons who have the disease are seen as wicked or evil doers who have been punished by God for their misdeeds in society. Such people lose the sympathy and respect of others in the community.

In that regard, it may not be too strange because in society in general, women are more associated with witchcraft than men (Foxcroft, 2009). This perception pertains to Ghana as well. So when a woman is afflicted by the disease the general conclusion is more likely to be that she is a witch or is under a curse and may consequently suffer divorce including other forms of indignity. The link to the higher level of divorce for women is that in Ghana, it is generally the man who approaches the woman with a proposal for marriage. Similarly, in Ghanaian society, it is generally more permissible for males to be divorced, and to have multiple sexual relationships than is the case for females (Oppenheim, 1994; Quadri, 2006). In all these instances, it becomes easier for a physically disfigured and a socially dishonoured wife to become disfavoured in the eyes of her husband and consequently suffer divorce than is the reverse.

Conversely, in terms of respect, more men than women felt they have lost respect in the eyes of people (83.3\%). Again this emanates from the residents of the study communities' perception of the disease and its cause as discussed above. Men are generally esteemed higher in Ghanaian societies. Thus, to be afflicted with a disease associated with witchcrafts and curses, the male patients' ego may be more affected by the ramifications of the disease.

\section{DISCUSSIONS}

\section{Implications for Poverty Reduction}

BU is a slow, secretive, but steady disease. When unnoticed for a long time it literally eats the flesh of its victims and destabilise the resources of households. Treatment of the disease may be 
free, but this is only comforting in the short term. The impact of the disease in the long run defies poverty reduction efforts. BU may not be as devastating as HIV/AIDS, because it does not put in its victims the fear of death, but its potential to draw one closer to poverty is rather harsh. Perhaps not only because its treatment is very expensive, but also because more often than not victims come out of the treatment with limited functional limbs (sometimes involving amputations). Such people are unable to work thus becoming liabilities on their households and increasing the dependency burden in society. Besides, the long periods of hospitalization means the loss of manpower--of the patient as well as the caregiver. When this straddles more than one agricultural season, coupled with an inability to mobilize communal labour, it means two things: a reduction in the labour force of the household, and a reduction in the size of the cultivated land of the household. The implication of this for the future is a reduction in farm output and a subsequent threat to household food security.

Even though treatment at the DHC is free, a troubling source of direct cost households had to contend with was the cost of transportation. Similar assertions with respect to BU have been made in Australia (Drummond \& Butler, 2004) and Cameroon (Ndobe \& Ghorbti, 2008; Peeters, Boock, Peeters, Hausmann-Muela, Toomer \& Ribera, 2008) regarding the free treatment for BU. In the Ga West District most of the endemic communities are in remote rural areas with poor access roads to the district capital where the BU treatment center is located. Most rural communities are serviced by just one minibus that moves in and out no more than two times a day, usually in the mornings and evenings. With the exception of two communities (i.e., Obom and Weija), the other sub-districts that have Government of Ghana health posts, BU patients from other rural communities have to commute to the district capital for health care everyday (especially for wound dressing). This involved huge cost to households.

In direct economic terms, the high indirect costs involved in seeking health care by way of transportation costs for an afflicted individual, and usually, an accompanying family member who serves as a caregiver to the BU patient is deeply troubling for such ordinarily low income and/or poverty stricken persons and households. For our respondents, the implication of BU affliction for poverty is critical considering that nearly all (96.5\%) of the affected household heads are self-employed or unemployed and do not have the chance to benefit from sick leave which is usually given with the necessary financial entitlements in formal employment settings. In Ghana, self-employed persons generally do not make provision ahead of time for sickness benefits. Given that there are negligible social benefit packages for economically vulnerable persons in Ghana, the economic plight of persons such as those we studied in coping with the economic costs of BU infection would be enormous. More so, considering that over 52 per cent of the household heads involved in the study and who had been incapacitated by BU were farmers, the economic burden of the disease can only be aptly attested through a rigorous econometric analysis since typically, it would not be easy to find persons to farm on their behalf in the short run. Thus, in both direct and indirect ways, the BU affected households we studied bore strong economic burden of the disease; both for the heads of households, whether they were afflicted personally or not, and also for their dependents, both afflicted and otherwise.

The economic value of time lost to hospitalization and traveling to and from the hospital for care is huge. The mandatory stay in the hospital is a source of huge time lost to households. In many cases households lost two active household members to BU treatment as one is required to accompany the victim or regularly visit the hospitalized victim at the hospital.

We also found that the economic cost of BU may not be the only burden that households had to endure. Individual victims and their households lived through trauma arising out of societal prejudice about the cause of the disease. This burden may even be weightier than the economic cost of the disease. This has negatively affected people's preparedness to report for treatment promptly. Several victims indicated that they are now being avoided by even their closest 
friends. Others suffered broken relations (experienced divorce) because of the disease. This confirms an earlier finding by Stienstra and associates (2002) about BU causing broken homes.

The deep stigma associated with the disease is another force to reckon with. BU-related stigma has a lot of negative effects on treatment-seeking behavior, such as seeking orthodox health care even though it is free. Stigma resulting from disfiguring of parts of the body causes affected individuals to avoid free government clinics leading to worsened illness, reduced career aspirations, and ultimately, an inexorable downward spiral to poverty (Pereira, Whitehead, Molyneux, Weerasooriya \& Guanatileke, 2007). There is a constant struggle by BU-infected persons and their households to cope with the stigma associated with the disease. Some of the coping strategies adopted included avoiding people and living in isolation. But these strategies rather perpetuate the stigma. Miller and Kaiser (2001) noted that avoiding highly prejudiced people may be an excellent strategy if the stigmatized person has little to gain by interacting with these people. But in this case the infected person needs other people in the community for support on farms and for other activities. Sometimes, the BU impoverished households needed to borrow money from neighbors and extended family members to cope with their struggle with the disease. Clearly, avoiding and hiding from the very persons that the BU affected victims need cannot be a sustainable strategy.

If we concede that BU largely affects children in their prime (Asiedu \& Etuaful, 1998; Amofah et al, 2002; Kofie, Attua \& Nabila, 2008) and most probably in school, we will appreciate more intensely the future poverty implications of BU. Children are affected in two main ways: first as victims and second as caregivers. But the sources of possible future poverty can be seen in three ways. First, if children are victims, then they are likely to suffer disruption of school education due to the prolonged morbidity associated with the treatment of the disease. Secondly, complications such as amputations and contracture deformities common among children will mean that children will not be able to work (Asiedu \& Etuaful, 1998). These children will grow into adulthood and may become a burden on society. Thirdly, as care givers, children also encounter disruption of formal education in the process. More worrying, children sometimes assume family headship roles at a tender age when their parents become the victims of BU incapacitation. These affect their growth and general preparedness for life.

From the foregoing, our findings have shown that BU resulted in poverty for our household respondents, both directly and indirectly. It is important to remember that already, these households were at a rather low rung on the financial ladder in Ghana. Directly, financial losses were incurred on transportation for purposes of going to seek health care for the BU infected person, and usually, an accompanying family member. In instances where care was sought outside the DHC where it was free, cost of treatment had to be borne by the affected households. Indirectly, the loss of income to some of these persons who lost their jobs is a case in point. As mentioned already, at least 50 per cent of all the infected adults were household heads. Again, the loss of time and labour due to hospitalization, usually for more than one family member, the BU infection's physical and psychosocial sequelae, including the accompanying stigma and social seclusion which prevented some of the household members from working, as well as the opportunity cost of possible future viable employment for the children whose schooling were disrupted temporally and/or permanently are all forms of indirect financial losses which would further impoverish the affected families, within the short to medium term, and possibly, in the long run.

\section{CONCLUSION AND RECOMMENDATIONS}

We conclude from our findings that the socioeconomic costs of BU to the households we studied were enormous and manifested in three main ways: health, financial and socio-psychological. The stigma that emanated from the disease was probably the most difficult cost incurred by the households we studied. There obviously will be a complex synergy between the economic and 
social costs of BU to the households and individuals involved in the study, directly, indirectly and also in terms of related opportunity costs. These critical interaction mechanisms would affect the ability of the participating households to cope with the burden of BU. More importantly, this synergy would dictate the final costs of the disease borne by the households and individuals involved more than a researcher can calculate.

A key recommendation we make for immediate attention is to ensure the extension of frequent public transportation infrastructure to the hinterlands of the District, to reach the endemic communities and with the transport fare fixed at a considerably reduced rate. We encourage other health-related non-governmental organizations to support the government efforts at ridding the District of BU and supporting its victims. Affected households and indeed the entire endemic communities need to be targeted with intensive and extensive public education on the disease, particularly in the rural endemic areas and be encouraged to seek care at the DHC as soon as they notice unusual physical symptoms. Since traditional healers are typically the first point of call for health care for most of the BU patients, we recommend that the herbalists should also be educated on the symptoms of the disease and then used to educate people in the rural areas where they operate. These will enhance efforts at identifying the disease early enough to reduce its debilitating effects.

Regular home visits to BU affected households by health and social workers to give them care, as well as enrolling them in social protection programmes such as the Livelihood Empowerment against Poverty program (LEAP) and the indigent national health insurance is recommended. The Ghana Health Service and the Ministry of Health, particularly using the Community Health Planning Strategy (CHPS), should carefully delineate the epidemiology of BU in order to educate affected communities about it so as to reduce the psychological burden of the disease on affected victims. This will also facilitate efforts to control BU, to contribute to the Millennium Development Goals of controlling neglected tropical diseases (NTDs), and achieving sustainable poverty reduction.

\section{REFERENCES}

Adamba, C. and Owusu, A.Y. (2011). Burden of buruli ulcer: How affected households in a Ghanaian district cope. African Study Monographs, 32(1): 1-23.

Allison, K.W. (1998). Stress and oppressed category membership. In J. K. Swim and C. Stangor (Eds.). Prejudice: The target's perspective: (145-170). San Diego, CA: Academic.

Amofah, G., Asamoah, S., and Afram-Gyening, C. (1998). Effectiveness of excision of preulcerative Buruli lesions in field situations in a rural district in Ghana. Tropical Doctor, 28: 8183.

Amofah, G. K., Bonsu, F., Tetteh, C., Okrah, J., Asamoa, K., Asiedu, K., and Addy, J. (2002). Results of a national case search. Emerging Infectious Diseases, 8: 167-170.

Asiedu, K. and Etuaful, S. (1998). Socioeconomic implications of Buruli ulcer in Ghana: A threeyear review. American Journal of Tropical Medicine and Hygiene, 59: 1015-1022.

Awusabo-Asare, K. and Anarfi, J. K. (1997). Health seeking behaviour of persons with HIV/AIDS in Ghana. Health Transition Review, 7(Suppl): 243-256.

Brown, L., Trujillo, L., Macintyre, K. (2001). Interventions to reduce HIV stigma: What have we learned? Horizons Population Council, 4-6. [online]. Available: http://www.popcouncil.org/pdfs/horizons/litrvwstigdisc.pdf. DA: 14th December 2010. 
Clark, R., Anderson, N. B., Clark, V. R., and Williams, D. R. (1999). Racism as a stressor for African Americans: A biopsychosocial model. American Psychologist, 54: 805-816.

Coetzee, M. and Spangenberg, J. J. (2003). Coping and quality of life in people with HIV/AIDS: A review. Acta Academica, 35 (3): 205-222.

Ding, S., Chen, Y., Feng, Li and Li, Zhe. (2008). Prevalence of illness and household ill-health risk coping strategies in rural China: A Chinese literature review. Studies in Health Policy Organization and Policy, 23: 55-82

Drummond, C. and Butler, James R. G. (2004). Mycobacterium ulcerans treatment costs, Australia. Emerging Infectious Diseases, 10 (6) [online]. Available: www.cdc.gov/eid. DA: 4th January 2011.

Etuaful, S., Carbonnelle, B., Grosset, J., Lucas, S., Horsfield, C., Phillips, R., Evans, M., Ofori-Adjei, D., Klutse, E., Owusu-Boateng, J., Amedofu, G.K., Awuah, P., Ampadu, E., Amofah, G., Asiedu, K. and Wansbrough-Jones, M. (2005). Efficacy of the combination rifampin-streptomycin in preventing growth of Mycobacterium ulcerans in early lesions of Buruli ulcer in humans. Antimicrobial Agents Chemotherapy, 49: 3182-86.

Foxcroft, G. (2009). Witchcraft accusations: A protection concern for UNHCR and the Wider Humanitarian Community? Paper Presented to UNHCR. Lancaster, United Kingdom: Child Rights Information Network [online)] Available: www.crin.org/docs/Stepping stones witchcraft.pdf. DA: 16th November 2010.

Hoffman, M. A. (1996). Counseling clients with HIV disease, New York: Guilford Press.

Kofie, R. Y., E. M. Attua and J. S. Nabila. (2008). Poverty and socioeconomic consequences of Buruli ulcer (Mycobacterium ulcerans) in the Ga West District of Ghana. Norsk Geografisk Tidsskrift-Norwegian Journal of Geography, 62: 210-221.

Makoae, L. N., M. Greeff, R. D. Phetlhu. L. R. Uys and J. R. Naidoo. (2008). Coping with HIV/AIDS stigma in five African countries. Journal of the Association of Nurses in AIDS Care, 19 (2): 137146.

Miller, C. T. and C. R. Kaiser. (2001). A theoretical perspective on coping with stigma. Journal of Social Issues, 57 (1): 73-92.

Montoro, E., V. Capo, M. E. Rodriguez, A. Ruiz, A. Llop. (1997). Buruli Ulcer in Ghana. Memórias do Instituto Oswaldo Cruz, 92 (1): 31-32.

Mumma, G.A.; Whitney, E.A.S.; Dadzie, F.; Etuaful, S. and Ampadu, E. (2003). Economic burden of Buruli Ulcer in Ghana. Paper Presented at the $6^{\text {th }}$ WHO Advisory Group Meeting on Buruli Ulcer; March 10-13; Geneva, Switzerland: WHO.

Ndobe, E. J. and N. Ghotbi. (2008). A review of the epidemiology and clinical presentation of Buruli ulcer in Akonolinga and Ayos - Cameroon. Tropical Medicine and Health, 36 (3): 121126.

Peeters, G. K., A. U. Boock, H. Peeters, S. Hausmann-Muela, E. Toomer and J. M. Ribera. (2008). 'It is me who endures but my family that suffers': Social isolation as a consequence of the household cost burden of buruli ulcer free of charge hospital treatment. PLoS Neglected Tropical Diseases, 2 (10): e321. 
Perera, M.; M. Whitehead; D. Molyneux, M. Weerasooriya and G. Guanatileke. (2007). Neglected patients with a neglected disease? A qualitative study of lymphatic filariasis. PLoS Neglected Tropical Diseases, 1: e128.

Russell, S. (1996). Ability to pay for health care: Concepts and evidence. Health Policy and Planning, 11:219-237.

Sauerborn, R.; A. Adams and M. Hien. (1996). Household strategies to cope with the economic costs of illness. Social Science and Medicine, 43: 291- 301.

Stienstra, Y., W. T. A. van der Graaf, K. Asamoa and T. S. van der Werf. (2002). Beliefs and Attitudes toward Buruli Ulcer in Ghana. American Journal of Tropical Medicine and Hygiene., $\underline{67}$ (2): 207-213.

WHO, (2004). Provisional guidance on the role of specific antibiotics in the management of Mycobacterium ulcerans disease (Buruli ulcer). Available:

http://whqlibdoc.who.int/hq/2004/WHO_CDS_CPE_GBUI_2004. DA: July 12, 2010.

WHO. (2006). Guidelines for controlling Buruli ulcer in the African Region. Harare: WHO Regional Office for Africa.

Wilkes, A., Y. Hao, G. Bloom and G. Xingyuan. (1997). Coping with the Costs of Severe Illness in Rural China. Brighton, United Kingdom: Institute of Development Studies (IDS) Working Paper No. 58. 